\title{
INTEGRATED TRIZ WITH QFD APPLIED TO AUTOMOTIVE VALVE INDUSTRY
}

\author{
G. B. L. SILVA, G. A. S. MARTINEZ*
}

Escola de Engenharia de Lorena, EEL-USP, 12.602-810 Lorena, Brazil

gustavo.martinez@usp.br*

Received 13/12/2017 - Accepted 22/01/2018

DOI: $10.15628 /$ holos.2018.6669

\section{ABSTRACT}

Understanding and assisting the clients in a more efficient way are paramount to maintain and to improve the relationship between the company and their customers. Quality Function Deployment has been used to understand the requirements of the customers. However, some requirements face technical obstacles in relation to the service provided. Theory of Inventive Problem Solving was developed to find innovative solutions to technical problems in products and process. This report describes a method that integrates Quality
\end{abstract}

Function Deployment with Theory of Inventive Problem Solving, which requires technical innovation specified from an analysis of customers' needs. Then, the technical problems to be solved are defined by quality characteristics, and technical innovation is executed by applying Theory of Inventive Problem Solving. Results showed efficiency on identifying customer's requirements, reoccurring problems and finding better and innovative solutions.

KEYWORDS: Quality Function Deployment (QFD); Theory of Inventive Problem Solving (TRIZ); Consumer Input. 


\section{INTRODUCTION}

The global market is more and more competitive; therefore, it is paramount that companies improve the quality of their products and seek new ways of satisfying their customers in a more effective way. Quality and efficient service generate client satisfaction, which makes companies grow in comparison to their competitors.

Customer service can be improved by a tool developed in Japan in the 60's, which deals with the "Voice of the Customer" named Quality Function Deployment (QFD). QFD is greatly used by most Japanese companies because it allows the understanding of customers' requirements, as data source to new strategies and business (Ghiya, Kinnar k., Bahill, A. Terry \& Chapman, Willian L, 1999; Akao, 2004).

The main tool of QFD is a House of Quality (HOQ) that relates to quality characteristics of customers' requirements. HOQ is divided in seven parts (Franceschini, 2015):

-Client requirements: These are the system entries; a qualitative research is carried out to listen to the customers to understand their real needs.

-Quality characteristics: These characteristics define the quality that the final product should have, or any other business aspects.

-Market analysis: Market analysis compares a determined customer requirement with competitive companies from determined segment.

- "Quality roof": Relates quality characteristics and how much they depend on each other; the increase of a determined characteristic may influence the reduction or increase of others.

-Matrix of Relationships: It is the most important part of Quality House. Here, relations are defined between the requirements of the customers and quality characteristics.

-Consumer value: Use the value that customers give to their requirements. Defines an absolute scale of how much we are doing good in that field or in that determined requirement.

-Absolute weight and relative weight: The sum of degree of relationship is considered to calculate the relative weight; requirements of the customer and characteristics of quality are multiplied by the value given by the consumer, according to Eq. 1, where VC is the consumer value and GR is the degree of relationship between the requirements of the customer and the characteristics of quality.

$$
\text { AbsoluteWeight }=\sum(V C \times G R)
$$

The complete set of behavior can be calculated by the absolute weight value in relation to each characteristic. The classification can be defined by knowing the relative weight to each quality characteristic and, then, to propose respective improvements giving priority to items of higher relative weight. 
Normally, client requirements find obstacles in the product or processes. In these cases, innovative approach for recurrent problems help companies to improve product quality and services, and gain visibility in the market (Mello et al., 2013).

The Theory of the Solution of Inventive Problems (TRIZ) is a systematic methodology that finds solutions to problems, especially in the field of engineering, in which existing problems can be related to the Project, products and/or processes, with innovative solutions (Nikulin \& Becker, 2015). It is based on technical principles, contradictions, evolution, ideology and resources (Savransky, 2000).

Several tools compose the TRIZ methodology, among them: the 40 Inventive Principles (IP), 39 Engineering Parameters (EP), Contradiction Matrix (CM), 4 Principles of Separation, Su-Field triangle, 76 Standard solutions, among others (Altshuller, 1996).

The 40 IPs are suggestions to possible inventive solution to the problem in question that occurred from the generalization of some solutions found in diverse fields (Carvalho \& Black, 2001). These principles can be applied in a direct mode in the solution of problems using the CM.

The CM is a tool, which was developed to identify the 40 IPs and can be applied to solve determined problems. It is necessary a technical contradiction that needs to be described in the form of EP to use it. Such EPs are the characteristics involved in the problem. Therefore, the contradiction occurs when a determined parameter is improved in detriment of the other.

Integration of methodologies QFD and TRIZ is a powerful instrument to improve products and processes because QFD indicates which products and processes require improvement, according to the customer, and TRIZ proposes innovative solutions with the aim of gaining market (Filgueira, 2005; Domb, 1997; Shahin, 2016; Wang, 2016; Caligiana, Gianni, Liverani, Alfredo, Francia, Daniela, Frizziero, Leonardo \& Donnici, Giampiero., 2017; Jafari, 2017; Santos, Leonardo B., Martínez, Guery A.E. \& Martínez, Gustavo A.S.,2017).

The purpose of this work is to feature the viability of combining the use of TRIZ and QFD to improve the process of packing in an automotive-chain industry.

\section{METHOD}

This work uses the methodology "ex-post facto", which resembles to an experimental methodology. However, there is no possible to rework independent variables, only to analyze the data previously collected.

Data was collected during a personal interview at the end of 2014, using the Customer Relationship Review (CRR), of an automotive valve industry.

The CRR was divided in four areas (Business Relationship, Support, Quality \& Performance and Innovation) which had quantitative and qualitative questions (Table 1) that permit to understand how the customer notices the company, their expectations and the areas involved in comparison to the previous year (2013).

Data from customers' answers served as basis to design the HOQ, along with internal data from the company and the proper calculation, to prioritize the more important quality characteristics to the customer and the ones that require more attention by the company. Then, 
internal processes of the company were analyzed to identify problems that came from customers' more important characteristics.

Table 1 - CRR Discussion Topics

\begin{tabular}{|c|c|c|c|c|}
\hline & $\begin{array}{l}\text { Product Quality } \\
\text { and Performance }\end{array}$ & Support & Innovation & $\begin{array}{c}\text { Business } \\
\text { Relationship }\end{array}$ \\
\hline $\begin{array}{l}\text { Discussion } \\
\text { Topics }\end{array}$ & $\begin{array}{l}\text { How well does the } \\
\text { quality of our } \\
\text { products and/or } \\
\text { services meet } \\
\text { your needs? }\end{array}$ & $\begin{array}{l}\text { How well do } \\
\text { we support } \\
\text { your } \\
\text { business? }\end{array}$ & $\begin{array}{l}\text { How well do } \\
\text { we } \\
\text { demonstrate } \\
\text { an innovative } \\
\text { approach to } \\
\text { your } \\
\text { business? }\end{array}$ & $\begin{array}{l}\text { How well } \\
\text { does our } \\
\text { relationship } \\
\text { add value to } \\
\text { your } \\
\text { business? }\end{array}$ \\
\hline
\end{tabular}

Problems were described using EP and CM, as proposed by TRIZ. IP was found using a CM, which allows to elaborate innovative solutions to the problems of each characteristic. To evaluate the benefits of the methodology applied, a study was brought up to examine waste time during the processes and costs of each scenario before and after the proposed solution.

\section{RESULTS AND DISCUSSION}

In Figure 1 we have the comparative result between the years 2013 and 2014 relative to four fields of CRR. Results showed improvement in the field, with a unique exception of an indicator of relative worsening in the field of Business Relationship.

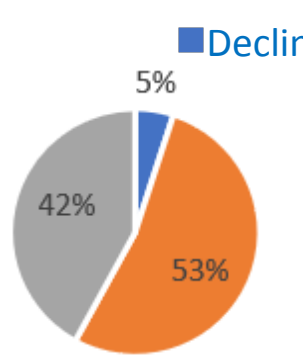

a)

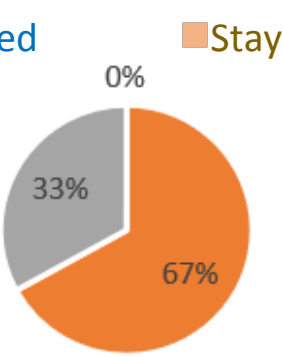

b)

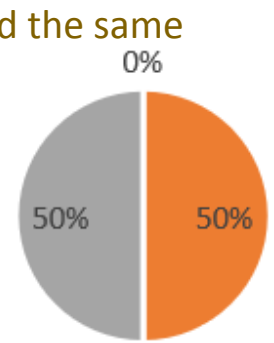

c)

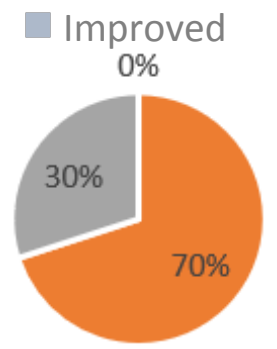

d)

Figure 1: Customer opinion relative to fields of CRR - a) business relationship; b) support; c) performance \& quality; d) innovation

Overall, results showed the need to improve the service quality. Although Business Relationship and Support areas have improved, customers revealed in their answers of these fields the need of improving customer service as well as an increase in the value-added business.

The knowledge of the process and the data analysis from four requirements of CRR define the requirements of the customer, as well as their weight or values (Table 2 ) required in the assembly of $\mathrm{HOQ}$ (Figure 2). 
Quality characteristics were established by the Quality sector of the company supported by the client voice (Table 3). Considering the relations between data of customers' requirements and quality characteristics, the weight of relationship levels (Table 4) were established.

Table 2: Requirements of clients and their weights

\begin{tabular}{l|c}
\hline \multicolumn{1}{c|}{ Customer requirement } & Consumer value \\
\hline Superior quality and final product & 5 \\
Low cost & 4 \\
Correct delivery time & 4 \\
Ease of relationship & 3 \\
Technological support & 2 \\
Speed of answer in relation to the needs & 4 \\
Absence of delivery problems & 5 \\
Cost reduction support & 3 \\
New packaging & 4 \\
\hline
\end{tabular}

Table 3: Quality characteristics and their trends

\begin{tabular}{l|c}
\hline \multicolumn{1}{c|}{ Quality characteristics } & Desired trend \\
\hline Number of superficial defects & Lower \\
Valve weight & - \\
Lead time of production & Lower \\
Failures in product testing & Lower \\
Parts per delivery & Higher \\
Presentation of solutions to clients & Higher \\
Quality of superficial treatment & Higher \\
Valve material & - \\
Days until closing price & Lower \\
Valves with defect generated in the delivery & Lower \\
Years of client fidelity & Higher \\
Percentage of scrap in production & Lower \\
\hline
\end{tabular}

Table 4: Levels of relationship

\begin{tabular}{l|c}
\hline \multicolumn{1}{c|}{ Level of relationship } & Corresponding value \\
\hline Strong relationship & 5 \\
Medium relationship & 3 \\
Weak relationship & 1 \\
Null relationship & 0 \\
\hline
\end{tabular}

Because of $\mathrm{HOQ}$ (Figure 2), we have the relevance of each quality characteristics (Table 5) stablished by the Quality area of the company and supported by the voice of the customer, which identifies the need of improvement in Years of Fidelity of Clients (relative relevance 1), Valve with 
Defects generated in the delivery (relative relevance 2). Consecutively, problems involving each of these characteristics were identified.

Time reduction spent between the opening of requested price by the customer and the budget submission (Table 6 ) is the required improvement in the characteristic of Years of Fidelity of Clients

The delay is in the spreadsheet completion and the collecting information from Engineering and Controllership. This happens because the company uses two methods of pricing, the Costumer Relationship Manager (CRM), which is a system of global pricing; and the critical analysis of pricing, which is a pricing system used in the industry where this work was performed. Using the critical pricing analysis, it is possible to obtain the price of each part produced, however to validate this price, it is necessary to include all information on the CRM. When the inclusion of information at the CRM occurs, a higher time demand also occurs because it does not contain all the required information to its completion, that is, the lack of information generating a higher time of pricing closure.

The existing contradiction in this system is the lack of information (EP-24-Loss of information), which must be improved, and the lack of time (EP-25-Waste of time), which is worsened because of all the missing information required to the inclusion of the system CRM. The use of CM generates four IPs: IP-24-Mediator, IP-26-Copying, IP-28-Replacement of a mechanical system and IP-32-Changing the color. 


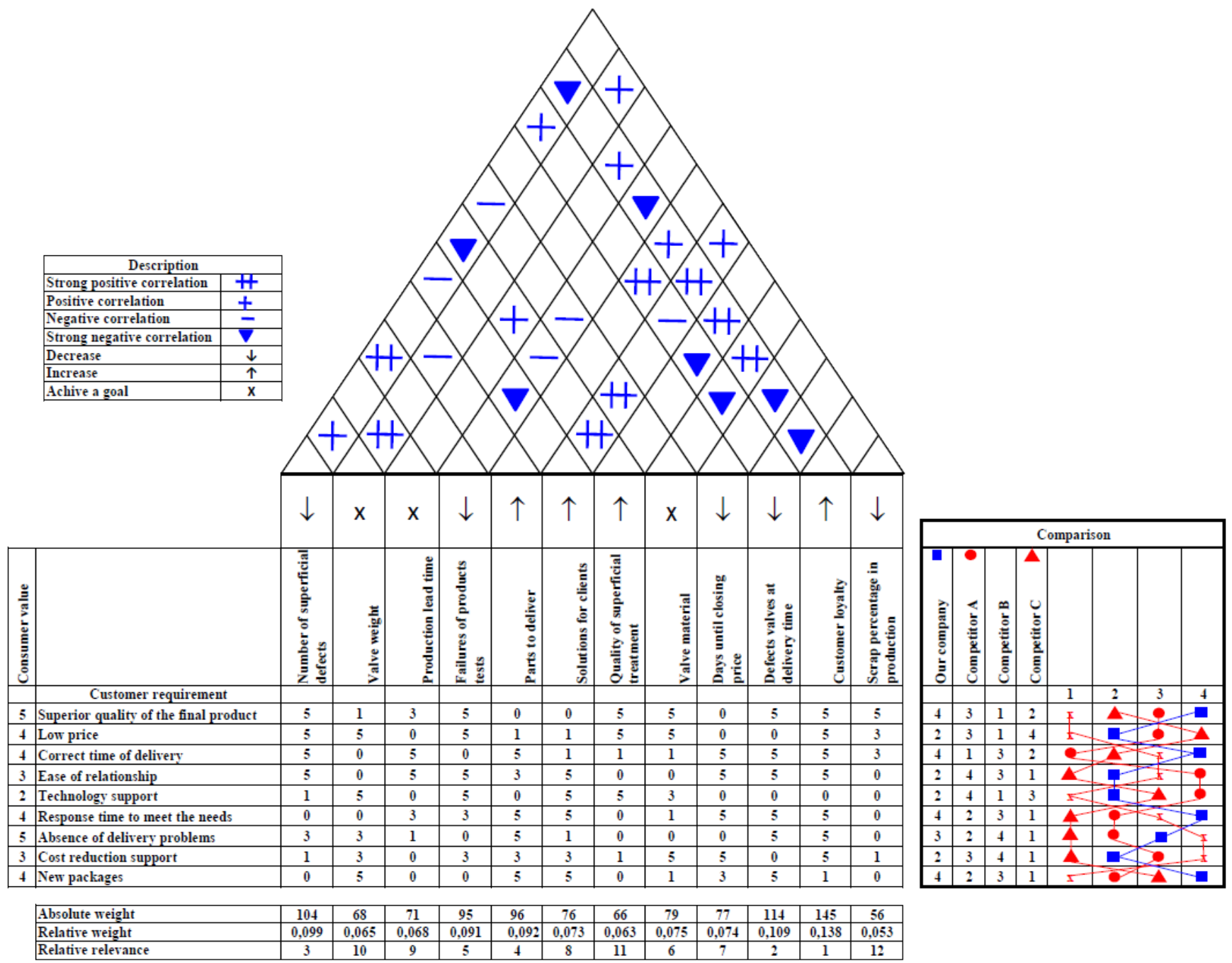

Figure 2: Resulting $\mathrm{HOQ}$

Table 5: Relevance of quality characteristics

\begin{tabular}{c|l}
\hline Relevance & \multicolumn{1}{|c}{ Quality characteristics } \\
\hline 1 & Years of fidelity of clients \\
2 & Valves with defects generated in the delivery \\
3 & Number of superficial defects \\
4 & Parts to deliver \\
5 & Failures of products tests \\
6 & Valve material \\
7 & Days until closing price \\
8 & Presentations of client solutions \\
9 & Lead time of production \\
10 & Valve weight \\
11 & Quality of superficial treatment \\
12 & Scrap percentage in Production \\
\hline
\end{tabular}


Table 6: Activities and time of budget process

\begin{tabular}{l|c}
\hline \multicolumn{1}{c|}{ Activity } & Time (h) \\
\hline Pricing request & 0 \\
Opening of critical analysis of budget & 04 \\
Spreadsheet completion & 32 \\
Kickoff meeting & 04 \\
Global Management Alignment & 12 \\
Financial analysis & 16 \\
Information of engineering, controllership, PCM & 48 \\
Target Cost Analysis & 04 \\
Approval of budget & 04 \\
Commercial proposal preparation & 08 \\
Customer proposal delivery & 0 \\
\hline
\end{tabular}

The most adequate approach to solve the problem is to use intermediation (IP-24Mediator), which refers to the use of process or intermediate object.

In the budget process, a form of critical budget analysis in which all areas of the company include the necessary information to reach the final price of the part is used. Loss of information problem is solved by using a form of critical analysis including the information necessary to conclude the budget system. CRM is not present in the form. The analysis of the budget process proved that the increase in the number of entries would reduce the action of the process, which leads to decrease of time between the opening and closure of the budget. Thus, information of critical analysis of pricing was included. As a result, we have a decrease in time between the opening and closure of budget (Table 7).

Table 7: Gains with the new model of pricing

\begin{tabular}{l|l|l}
\cline { 2 - 3 } & \multicolumn{2}{c}{ Model } \\
\cline { 2 - 3 } & \multicolumn{1}{c}{ Current } & \multicolumn{1}{c}{ Proposed } \\
\hline Days of pricing in open & 21 days & 14 days \\
Average quantity of files in the system & $5.1 /$ pricing & $3 /$ pricing \\
Average weight of files in the system by pricing & $2.86 \mathrm{Mb} /$ pricing & $1.5 \mathrm{Mb} /$ pricing \\
\hline
\end{tabular}

After evaluating the quality characteristic of Valve with Defects generated in the delivery (relevance 2), problems were detected in the use of packing, that in many cases, are not appropriate to the type of transport (ex.: maritime transport) or required quantity (multiple needed).

EP's found for the best solution of oxidation during the transportation consisted on the improvement of the resistance (EP-14-Strength). The oxidation, during the maritime transport and the worsening of liability (EP-27-Reliability), resulted in the IP's previous damping or previous protection (IP-11-Cushion in advance) and localized quality (IP-3-Local quality). 
The principle of previous damping indicates the necessity to compensate possible unreliable actions of the system or even taking preventive actions of the object a priori. Previous protection, recommended on this case, is by inserting some protective elements in the own packing to avoid oxidation of parts.

The resulting solution of IP-11 was the inclusion of paper and plastic bag with inhibitors of corrosion volatiles ( $\mathrm{VCl}$ ) for export packages, as shown in Figure 3.

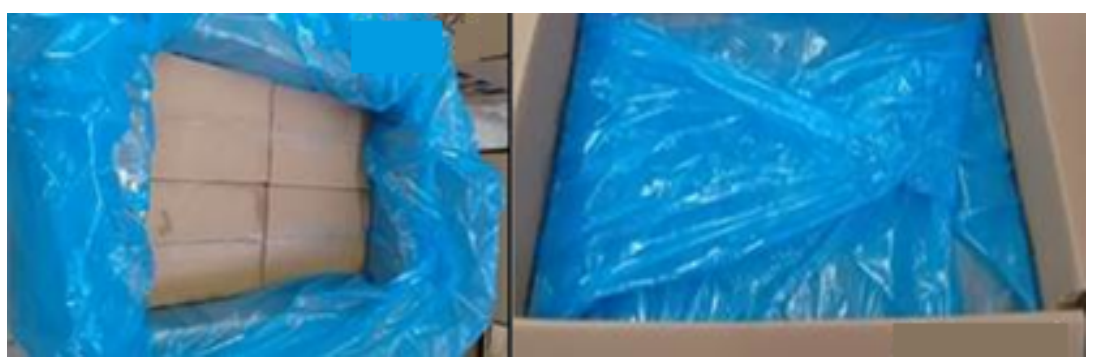

Figure 3: Packing with VCl

Packages with multiple differences as required by the customer, the EP to be improved is the capacity or productivity (EP-39-Productivity), and the EP worsening is the form (EP-12-Shape), that results in the IP's recurrence (IP-14-Spheroidality), previous action (IP-10-Prior action), disposal and regeneration (IP-34-Rejeiting and regenerating parts) and composite material use (IP-40-Compsite materials).

IP-10 was applied in the package holding 100 valves, disposed in two layers (one side by side) with 50 (Figure 4.a). This package generates additional work to the operator, because after filling a layer, it was necessary to close the box and turn it to fill in the other side. Rearranging the disposition of valves permitted to allocate the valves always at the same side of the box; without turning the box. The new disposition holds four layers of 35 valves each, increasing the number of total parts in the box to 140 (Figure 4.b), reducing $22 \%$ in the cost of package (Table 8).

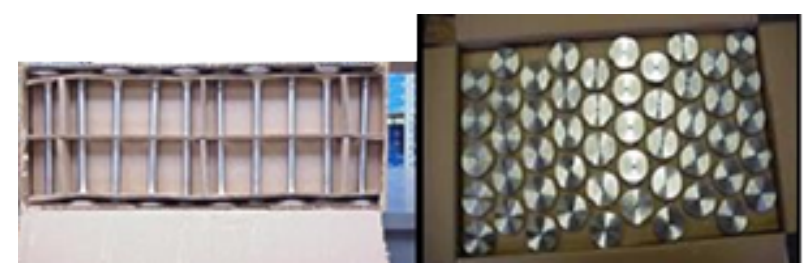

a)

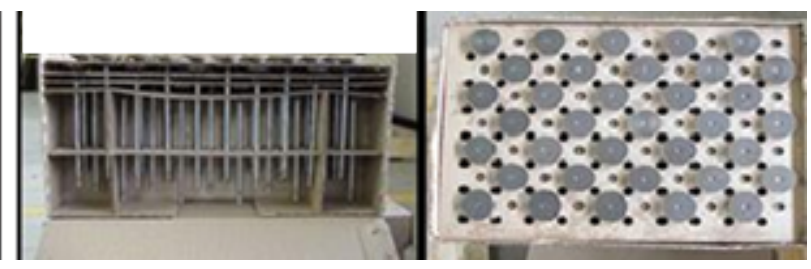

b)

Figure 4: Distribution of valves in the package - a) Initial package - 100 valves; b) Final package 140 valves 
Table 8: Comparison of prices of package

\begin{tabular}{l|c|c}
\hline \multicolumn{1}{c|}{ Package } & Initial & Final \\
\hline Parts per box (unit) & 100 & 140 \\
Boxes per pallet (unit) & 8 & 24 \\
Parts per pallet (unit) & 800 & 3360 \\
Box (R\$) & 4.56 & 7.11 \\
External box (R\$) & 15.48 & 21.98 \\
Pallet (R\$) & 16.00 & 24.50 \\
Bag VCI (R\$) & 3.99 & 6.42 \\
Total price (R\$) & 71.95 & 223.54 \\
Price per part (R\$) & 0.09 & 0.07 \\
Reduction per valve (\%) & \multicolumn{2}{|c}{22} \\
\hline
\end{tabular}

\section{CONCLUSIONS}

The integration of the methodology TRIZ with QFD resulted positive when applied to the studied problem.

The industrial gains resulting from integration of TRIZ with the QFD were: Environmental sustainable package and reduction; Reduction of $22 \%$ in the cost of package per valve; Increase of $40 \%$ of number of valves per package; Reduce shipping cost - less number of boxes; and Reducing cost and time.

We can conclude that the two methodologies combined were extremely effective to identify main aspects of the customer in terms of recurring problems and to find better and innovative solutions for them.

\section{REFERENCES}

Akao, Y. (2004). Quality Function Deployment: Integrating Customer Requirements into Product Design. New York, NY: Productivity Press, Inc..

Altshuller, H. (1996). And Suddenly the Inventor Appeared. Worcester, MA: Technical Innovation Center.

Caligiana, G., Liverani, A., Francia, D., Frizziero, L. \& Donnici, G. (2017). Integrating QFD and TRIZ for innovative design. Journal of Advanced Mechanical Design, Systems, and Manufacturing, 11(2). https://doi.org/10.1299/jamdsm.2017jamdsm0015

Carvalho, M.A. \& Black, N. (2001). Uso de conceitos fundamentais da TRIZ e do método dos princípios inventivos no desenvolvimento de produtos. 3o. Congresso Brasileiro de gestão de Desenvolvimento de Produto. Florianópolis, SC..

Domb, E. (1997). QFD and Tips/triz. Proceedings of the 3d International Symposium on QFD. Linkoping, Sweden.

Franceschini, F., Galetto, M., Maisano, D. \& Mastrogiacomo, L. (2015). Prioritisation of engineering characteristics in QFD in the case of customer requirements orderings. 
International Journal of Production Research, 53:13,3975-3988.

Filgueira, J.M. (2005), Avaliação de satisfação de cliente: proposta de utilizaçãodo coeficiente de correlação de concordância. Holos, 21, 47-56

Ghiya, K.K., Bahill, A.T \& Chapman, W.L. (1999). QFD: Validating robustness. Quality Engineering, 11(4), 593-611. http://doi.org/10.1080/08982119908919280

Jafari, M. \& Zarghami, H.R. (2017). Effect of TRIZ on enhancing employees creativity and innovation. Aircraft Engineering and Aerospace Technology, 89(6), 853-861. https://doi.org/10.1108/AEAT-01-2016-0004

Mello, J., Martins, W.L.S., Vaz, C.R., Francisco, A.C. \& Selig, P.M. (2013). Gestão da inovação em organizações: um estudo de caso em uma empresa de pequeno porte no segmento metalúrgico na cidade de Curitiba-PR. Holos, 29(3)

Nikulin, C. \& Becker, G. (2015). Una Metodología Sistémica y Creativa para la Gestión Estratégica: Caso de Estudio Región de Atacama-Chile. Journal of Technology Management \& Innovation, [S.I.], 10(2), p. 127-144. http://dx.doi.org/10.4067/S0718-27242015000200009.

Santos, L.B., Martínez, G.A.E. \& Martínez, G.A.S. (2017). Modelo para Solução Criativa de Problemas. Espacios, 38(53), 6.

Savransky, S.D. (2000). Engineering of Creativity: Introduction to TRIZ Methodology of Inventive Problem Solving. CRC Press.

Shahin, A., Iraj, E.B. \& Shahrestani, H.V. (2016). Developing House of Quality by integrating top roof and side roof matrices and service TRIZ with a case study in banking services. The TQM Journal, 28(4) pp.

Wang, C-H. (2016). Incorporating the concept of systematic innovation into quality function deployment for developing multi-functional smart phones. Computers \& Industrial Engineering, 107, 367-375. https://doi.org/10.1016/j.cie.2016.07.005 